\title{
As tendências pedagógicas e a prática educativa nas ciências da saúde
}

\author{
Pedagogical approaches and educational \\ practices in health sciences
}

Adriana Lenho de Figueiredo Pereira 1

1 Serviço de Treinamento e Avaliação de Enfermagem, Hospital Universitário Pedro Ernesto, Universidade do Estado do Rio de Janeiro. Boulevard 28 de Setembro, 77, 3 o andar, Rio de Janeiro, RJ 20551-030, Brasil. adrianalenho@bridge.com.br

\begin{abstract}
Educational practices are widely used in the health field, both in continuing education for health professionals and health education for the general population. These two fields intersect through the development of educational knowledge oriented by a set of target representations of man and society. Such representations are demonstrated by teaching/learning processes in the four main pedagogical trends in Brazil: traditional, renewed, conditioning-based, and liberating (or the Paulo Freire approach). Based on their respective principles, methods, and individual and social consequences, we contend that liberating pedagogy can produce better results than the others by allowing the student's active participation in the learning process, thus fostering continuous development of human skills in both the health services clientele and health workers.
\end{abstract}

Key words Continuing Education; Educational Models; Health Education

Resumo As práticas educativas são amplamente utilizadas na área da saúde, tanto na formação contínua dos profissionais que atuam nesta área quanto no campo da educação em saúde para a população em geral. A interseção destes dois campos de conhecimento humano se dá através do desenvolvimento de práticas educativas norteadas por um conjunto de representações de homem e de sociedade que se quer efetivar. Essas representações são demonstradas através da discussão dos processos de ensino-aprendizagem utilizados nas tendências pedagógicas mais dominantes em nosso meio: a pedagogia tradicional, renovada, por condicionamento e a libertadora. A partir dos princípios, métodos e conseqüências ao nível individual e social de cada pedagogia apresentada, concluímos que a pedagogia libertadora pode produzir melhores resultados que as demais correntes pedagógicas estudadas, por possibilitar a participação ativa do educando no processo da aprendizagem, propiciando o desenvolvimento contínuo das habilidades humanas tanto da clientela quanto dos trabalhadores da área de saúde.

Palavras-chave Educação Continuada; Modelos Educacionais; Educação em Saúde 


\section{Introdução}

A educação e a saúde são espaços de produção e aplicação de saberes destinados ao desenvolvimento humano. Há uma interseção entre estes dois campos, tanto em qualquer nível de atenção à saúde quanto na aquisição contínua de conhecimentos pelos profissionais de saúde. Assim, estes profissionais utilizam, mesmo inconscientemente, um ciclo permanente de ensinar e de aprender.

A prática educativa em saúde, aqui, referese tanto às atividades de educação em saúde, voltadas para o desenvolvimento de capacidades individuais e coletivas visando à melhoria da qualidade de vida e saúde; quanto às atividades de educação permanente, dirigidas aos trabalhadores da área de saúde através da formação profissional contínua. Lembramos que muitas práticas de saúde requerem práticas educativas. As ações de saúde não implicam somente a utilização do raciocínio clínico, do diagnóstico, da prescrição de cuidados e da avaliação da terapêutica instituída. Saúde não são apenas processos de intervenção na doença, mas processos de intervenção para que o indivíduo e a coletividade disponham de meios para a manutenção ou recuperação do seu estado de saúde, no qual estão relacionados os fatores orgânicos, psicológicos, sócio-econômicos e espirituais. Consideramos, ainda, que pode-se exercer a prática de saúde em qualquer espaço social, visto que o campo da saúde é muito mais amplo do que o da doença.

Tomando como princípio norteador a saúde integral, utilizamos o referencial da promoção da saúde, que visa elaborar e implementar políticas públicas saudáveis; criar ambientes favoráveis à saúde; reforçar ação comunitária; desenvolver habilidades pessoais e reorientar o sistema de saúde, conforme as diretrizes estabelecidas pela Carta de Ottawa (OMS, 1986). Este documento constitui-se ainda em nossos dias um referencial neste campo. Para Candeias (1997), há, no campo da promoção da saúde, uma combinação de apoios educacionais e ambientais que visam a atingir ações e condições de vida que garantam saúde. Desta forma, práticas educativas adquirem relevância e imperiosidade nas ações de saúde voltadas para este campo de ação. Essas práticas são o objeto das ações da educação em saúde, que tem como referenciais as concepções de saúde e de educação pautadas no desenvolvimento das potencialidades humanas, no potencial de transformação da realidade, sendo integrantes dos direitos fundamentais da pessoa humana.
Ressaltamos que a prática educativa em saúde não se restringe às ações no âmbito da atenção primária, como geralmente é entendida, mas se faz necessária nos três campos de atenção. Este pensamento é expresso no Relatório Final da XI Conferência Nacional de Saúde (CNS, 2000:165-166), no capítulo Democratização das Informações: "As Políticas de IEC (Informação, Educação e Comunicação) devem ... estar voltadas para a promoção da saúde, que abrange a prevenção de doenças, a educação para a saúde, a proteção da vida, a assistência curativa e a reabilitação sob responsabilidade das três esferas de governo, utilizando pedagogia crítica, que leve o usuário a ter conhecimento também de seus direitos; dar visibilidade à oferta de serviços e ações de saúde do SUS; motivar os cidadãos a exercer os seus direitos e cobrar as responsabilidades dos gestores públicos e dos prestadores de serviços de saúde".

Devido à crescente acumulação de conhecimentos e, como conseqüência, a necessidade de atualização constante do profissional de saúde, torna-se indispensável um processo de formação contínua que vise não somente à aquisição de habilidades técnicas, mas também ao desenvolvimento de suas potencialidades no mundo do trabalho e no seu meio social. Quanto este aspecto, no Relatório Final da XI CNS identifica-se a seguinte problemática em relação aos recursos humanos do sistema de saúde brasileiro: "Há ausência da academia nos processos de formação, re-qualificação $e$ capacitação dos Recursos Humanos para a nova realidade e modelos de gestão. Essa falta de qualificação profissional desmotiva e desgasta física e emocionalmente, acarreta dificuldades de relacionamento e impede a coesão das equipes de saúde e resulta na execução das tarefas sem planejamento, exigindo uma política de Educação Continuada aos profissionais" (CNS, 2000:47).

Identificados os pontos de interseção entre a educação e a saúde, passaremos a abordar algumas considerações sobre as práticas educativas.

Educar não significa simplesmente transmitir/adquirir conhecimentos. Existe, no processo educativo, um arcabouço de representações de sociedade e de homem que se quer formar. Através da educação as novas gerações adquirem os valores culturais e reproduzem ou transformam os códigos sociais de cada sociedade. Assim, não há um processo educativo asséptico de ideologias dominantes, sendo necessária a reflexão sobre o próprio sentido e valor da educação na e para a sociedade (Luckesi, 1994; Saviane, 1985). 
Já discirrida a importância da educação no campo da saúde, torna-se necessária a discussão sobre as concepções de práticas educativas. Essas concepções são norteadas pelas tendências pedagógicas, a forma pela qual é compreendido o processo de ensino-aprendizagem. Segundo o Ministério da Educação e Cultura (MEC, 1997), são dominantes no sistema educacional brasileiro: a tradicional, a renovada, a tecnicista e aquelas marcadas centralmente por preocupações sociais e políticas.

Tais tendências referem-se à forma predominante pela qual se efetua o processo educativo, muitas vezes os professores ou os instrutores de um mesmo cenário educativo podem utilizar processos pedagógicos diferentes e, portanto, haver uma mescla de tendências utilizadas.

\section{Pedagogia tradicional}

Nesta tendência pedagógica, as ações de ensino estão centradas na exposição dos conhecimentos pelo professor. O professor assume funções como vigiar e aconselhar os alunos, corrigir e ensinar a matéria. É visto como a autoridade máxima, um organizador dos conteúdos e estratégias de ensino e, portanto, o único responsável e condutor do processo educativo.

Há predominância da exposição oral dos conteúdos, seguindo uma seqüência predeterminada e fixa, independentemente do contexto escolar; enfatiza-se a necessidade de exercícios repetidos para garantir a memorização dos conteúdos. Os conteúdos e procedimentos didáticos não estão relacionados ao cotidiano do aluno e muito menos às realidades sociais.

Na relação professor-aluno, prevalece a autoridade do professor, exigindo uma atitude receptiva dos alunos e impedindo a comunicação entre eles. O professor transmite o conteúdo como uma verdade a ser absorvida. Os conteúdos do ensino correspondem aos conhecimentos e valores sociais acumulados pelas gerações passadas como verdades acabadas, e, embora a escola vise à preparação para a vida, não busca estabelecer relação entre os conteúdos que se ensinam e os interesses dos alunos, tampouco entre esses e os problemas reais que afetam a sociedade. A função primordial da escola, nesse modelo, é transmitir conhecimentos disciplinares para a formação geral do aluno, formação esta que o levará, ao inserir-se futuramente na sociedade, a optar por uma profissão valorizada (Luckesi, 1994; MEC, 1997).

Collares et al. (1999) e Behrens (1999) consideram que a prática pedagógica relacionada à reprodução do conhecimento está fortemente influenciada pelo paradigma da ciência newtoniana-cartesiana. Como conseqüência desta influência, a ação docente é fragmentada e assentada na memorização, os profissionais educadores têm dificuldades de utilizar outras formas de ensinar que não a de transmitir conhecimentos. Para Behrens (1999) este tipo de prática pedagógica ainda é freqüente na universidade brasileira. "O objeto cognoscível de que esse sujeito se apropria, "forma-o" pela incorporação não transformada dos conhecimentos adquiridos. Do ponto de vista da ciência clássica, a educação - como formação intelectual - forma os sujeitos transformando-os em seres a-históricos, racionais, em que o espaço para os acontecimentos está desde sempre afastado. Trata-se de negar a contingência da subjetividade para evitar o que ela supostamente seria: uma fonte de erros ou de perturbações" (Collares et al., 1999:207).

Bordenave (1999) sistematiza as repercussões dessa corrente pedagógica, tanto em nível individual quanto social, como descrito a seguir:

- Em nível individual: (a) hábito de tomar notas e memorizar; (b) passividade do aluno e falta de atitude crítica; (c) profundo "respeito" quantos fontes de informação, sejam elas professores ou textos; (d) distância entre teoria e prática; (e) tendência ao racionalismo radical; (f) preferência pela especulação teórica; e (g) falta de "problematização" da realidade.

- Em nível social: (a) adoção inadequada de informações científica e tecnológica de países desenvolvidos; (b) adoção indiscriminada de modelos de pensamento elaborado em outras regiões (inadaptação cultural); (c) individualismo e falta de participação e cooperação; e (d) falta de conhecimento da própria realidade e, conseqüentemente, imitação de padrões intelectuais, artístico e institucionais estrangeiros; submissão à dominação e ao colonialismo; manutenção da divisão de classes sociais (status quo).

\section{Pedagogia renovada}

A pedagogia renovada inclui várias correntes que, de uma forma ou de outra, estão ligadas ao movimento da pedagogia não-diretiva, representada principalmente pelo psicólogo Carl Rogers e pelo movimento chamado Escola Nova ou Escola Ativa (John Dewey, Maria Montessori, Ovide Decroly, Jean Piaget, Anísio Teixeira, entre outros) (Luckesi, 1994). 
Essas correntes, embora admitam divergências, assumem um mesmo princípio norteador de valorização do indivíduo como ser livre, ativo e social O centro da atividade escolar não é o professor nem os conteúdos disciplinares, mas sim o aluno, como ser ativo e curioso. O mais importante não é o ensino, mas o processo de aprendizagem. "Trata-se de "aprender a aprender", ou seja, é mais importante o processo de aquisição do saber do que o saber propriamente dito" (Luckesi, 1994:58).

O professor facilita o desenvolvimento livre e espontâneo do indivíduo, o processo de busca pelo conhecimento, que deve partir do aluno. Cabe ao professor organizar e coordenar as situações de aprendizagem, adaptando suas ações às características individuais dos alunos, para desenvolver capacidades e habilidades intelectuais de cada um. O professor estimula ao máximo a motivação dos alunos, despertando neles a busca pelo conhecimento, o alcance das metas pessoais, metas de aprendizagem e desenvolvimento de competências e habilidades. Desta forma, o processo de ensino é desenvolvido para proporcionar um ambiente favorável ao autodesenvolvimento e valorização do "eu" do aluno.

É uma tendência de ensino do início do século XX, na qual procurava estimular a curiosidade da criança para o aprendizado. Os jogos educativos, por exemplo, foram utilizados como estratégias de aprendizagem. O ambiente deveria ser dotado de materiais didáticos, estimulante e alegre, muito diferente do ambiente frio e formal da escola tradicional. O professor deveria trabalhar com pequenos grupos, de forma que a relação interpessoal dinamizasse o processo de ensino-aprendizagem. Como uma nova metodologia e embora muito difundida na época, na prática não se desseminou por todo o sistema de ensino. Segundo o MEC (1997), a idéia de um ensino guiado pelo interesse dos alunos acabou, em muitos casos, por desconsiderar a necessidade de um trabalho planejado, perdendo-se de vista o que se deve ensinar e aprender. Essa tendência, teve grande penetração no Brasil na década de 30, principalmente ensino pré-escolar (jardim de infância). Até hoje esta corrente influencia algumas práticas de ensino, com maior destaque na educação infantil, especialmente no campo da orientação educacional e da psicologia escolar.

\section{Pedagogia por condicionamento}

Nos anos 70, proliferou o chamado "tecnicismo educacional”, inspirado nas teorias behavioristas (Skinner, Gagné, Bloon e Mager) da aprendizagem e na abordagem sistêmica do ensino. Esta pedagogia se concentra no modelo da conduta mediante um jogo eficiente de estímulos e recompensas capaz de "condicionar" o aluno a emitir respostas desejadas pelo professor. A prática pedagógica é altamente controlada e dirigida pelo professor, com atividades mecânicas inseridas em uma proposta educacional rígida e passível de ser totalmente programada em detalhes (Luckesi, 1994).

Nesta tendência, a escola funciona como modeladora do comportamento através de técnicas específicas. À educação escolar compete organizar o processo de aquisição de habilidade, atitudes e conhecimentos específicos, úteis e necessários para que os indivíduos estejam integrados na máquina do sistema social global. A escola atua no aperfeiçoamento da ordem social vigente (o sistema capitalista), assim, o seu interesse imediato é de produzir indivíduos competentes (no âmbito da técnica) para o mercado de trabalho.

Os conteúdos de ensino são as informações, os princípios científicos, as leis, entre outros, ordenados em uma seqüência lógica e psicológica por especialistas. É privilegiado no ensino o conhecimento observável e mensurável, advindo da ciência objetiva, eliminando-se qualquer sinal de subjetividade. Os métodos utilizados são os procedimentos e técnicas necessários ao arranjo e controle do ambiente da aprendizagem a fim de que seja assegurada a transmissão/recepção das informações. A atividade de descoberta é função da educação, mas deve ser restrita aos especialistas, sendo sua aplicação de competência do processo educacional comum (Bordenave, 1999; Luckesi, 1994).

As conseqüências da pedagogia do condicionamento ou modelagem da conduta são assim descritas por Bordenave (1999) :

- Em nível individual: (a) aluno ativo, emitindo respostas que o sistema o permitir; (b) alta eficiência da aprendizagem de dados e processos; o aluno não questiona os objetivos nem o método, tampouco participa em sua seleção; (c) $\mathrm{o}$ aluno tem oportunidade de criticar as mensagens (conteúdos) do programa; (d) o tipo e a oportunidade dos reforços são determinados pelo programador do sistema; (e) tendência ao individualismo salvo quando o programa estabelece oportunidades de co-participação; (f) tendência à competitividade: $o$ aluno mais rápido ganha em status e em acesso a materiais ulteriores; e (g) tendência a renunciar à originalidade e à criatividade individuais: as respostas corretas são preestabelecidas.

- Em nível social: (a) tendência à robotização da população com maior ênfase na produtivi- 
dade e eficiência do que na criatividade e na originalidade; (b) costumes de dependência de uma fonte externa para o estabelecimento de objetivos, métodos e reforços: desenvolvimento da necessidade de um líder; (c) falta de desenvolvimento de consciência crítica e cooperação; (d) suscetilidade dos programas à manipulação ideológica e tecnológica; (e) ausência de dialética "professor-conteúdo", salvo em sessões eventuais de reajustes; (f) dependência de fontes estrangeiras de programas, equipamentos e métodos; (g) tendência ao conformismo por razões superiores de eficiência e pragmatismo utilitário.

A ênfase nos procedimentos e técnicas de ensino trouxe distorções no processo ensinoaprendizagem, como constata o MEC (1997:31): “A supervalorização da tecnologia programada de ensino trouxe conseqüências: a escola se revestiu de uma grande auto-suficiência, reconhecida por ela e por toda a comunidade atingida, criando assim a falsa idéia de que aprender não é algo natural do ser humano, mas que depende exclusivamente de especialistas e de técnicas. $O$ que é valorizado nessa perspectiva não é o professor, mas a tecnologia; o professor passa a ser um mero especialista na aplicação de manuais e sua criatividade fica restrita aos limites possíveis e estreitos da técnica utilizada. A função do aluno é reduzida a um indivíduo que reage aos estímulos de forma a corresponder a respostas esperadas pela escola, para ter êxito e avançar. Seus interesses e seu processo particular não são considerados e a atenção que recebe é para ajustar seu ritmo de aprendizagem ao programa que o professor deve implementar".

Esta tendência vem influenciando a formação dos profissionais de saúde, tanto que autores como Cordeiro \& Minayo (1997) citam o cliente como objeto e não como um sujeito da ação dos profissionais de saúde. Como objeto, as ações são centradas no seu corpo, órgão afetado. Apontam que na área de saúde é necessário integrar na formação de seus profissionais uma formação humanística. "Quando falo de formação humanística, refiro-me à necessidade de se considerar que doente é gente, que gente não é só corpo, que gente não é só pedaço, não é só órgão. O que estou reivindicando é o centro do pensamento médico seja a pessoa e não a especialidade em si. A especialidade é necessária, temos que ser técnicos altamente qualificados, mas tendo incorporado, como parte da atividade, a dimensão do humano, que deveria ser considerada nos currículos dos diferentes níveis de ensino" (Cordeiro \& Minayo, 1997:61).

\section{Pedagogias críticas}

No final dos anos 70 e início dos 80, a abertura política no final do regime militar coincidiu com intensa mobilização de educadores para buscar uma educação crítica, a serviço das transformações sociais, econômicas e políticas, tendo em vista superar as desigualdades sociais. Ao lado das denominadas teorias críticas, firma-se, no meio educacional, a "pedagogia libertadora" e da "pedagogia crítico-social dos conteúdos", defendidas por educadores de orientação marxista (MEC, 1997). Decidimos focalizar nossa atenção para a pedagogia libertadora ou da problematização por possibilitar uma prática educativa em saúde mais participativa, direcionada tanto à população, na educação em saúde, quanto a profissionais de saúde, na educação continuada.

Essa aderência deve-se ao fato de que falar em promoção da saúde é falar sobre incremento do poder (empowerment) comunitário e pessoal, através de desenvolvimento de habilidades e atitudes, conducentes à aquisição de poder técnico (saberes) e político para atuar em prol de sua saúde, como propõe a Carta de Ottawa (OMS, 1986). Laverack (2001) diz que este empowerment está diretamente relacionado ao desenvolvimento de programas que promovam nas comunidades uma consciência crítica sobre sua realidade vivida. $\mathrm{O}$ autor considera, ainda, que o método educativo de Paulo Freire é uma relevante contribuição para estes programas comunitários, denominando-o de $\mathrm{em}$ powerment education (Laverack, 2001).

A pedagogia da problematização tem suas origens nos movimentos de educação popular que ocorreram no final dos anos 50 e início dos anos 60, quando estes movimentos foram interrompidos pelo golpe militar de 1964; teve seu desenvolvimento retomado no final dos anos 70 e início dos anos 80. Nesta pedagogia, a educação é uma atividade em que professores e alunos são mediatizados pela realidade que apreendem e da qual extraem o conteúdo da aprendizagem, atingem um nível de consciência dessa realidade, a fim de nela atuarem, possibilitando a transformação social.

Na educação tradicional, denominada por Paulo Freire (2001) de "bancária”, o educando recebe passivamente os conhecimentos, tornando-se um depósito de informações fornecidas pelo educador. Educa-se para arquivar o que se deposita. A consciência bancária "pensa que quanto mais se dá mais se sabe”. Mas a experiência mostra que neste sistema só se formam indivíduos medíocres, por não haver estímulo para a criação (Freire, 2001). Na educa- 
ção renovada, pretendia-se uma libertação psicológica individual, sendo na realidade uma educação domesticadora, já que em nada contribui para desvelar a realidade social de opressão. Já a educação libertadora questiona concretamente a realidade das relações do homem com a natureza e com os outros homens, visando a uma transformação (Luckesi, 2001)

Nesta pedagogia, o método de ensino é realizado na forma de trabalho educativo, através dos grupo de discussão. O professor está ao mesmo nível de importância em relação aos alunos, visto que seu papel é animar a discussão. Dessa forma, o método de ensino se baseia na relação dialógica entre os atores da aprendizagem, tanto alunos quanto professor. Para Freire (2001), é através do diálogo que se dá a verdadeira comunicação, onde os interlocutores são ativos e iguais. A comunicação é uma relação social igualitária, dialogal, que produz conhecimento.

A aprendizagem se dá através de uma ação motivada, da codificação de uma situação problema, da qual se distancia para analisá-la criticamente. Aprender é um ato de conhecimento da realidade concreta, isto é, da situação real vivida pelo educando, que se dá através de uma aproximação crítica dessa realidade. $\mathrm{O}$ que é aprendido não decorre da imposição ou memorização, mas do nível crítico de conhecimento ao qual se chega pelo processo de compreensão, reflexão e crítica (Libâneo, 1983).

Bordenave (1999) apresenta o processo ensino-aprendizado nesta pedagogia utilizandose do método do arco criado por Charles Mangarez, que representa esquematicamente os passos na Figura 1.

Observamos neste diagrama o processo de ensino-aprendizagem que parte da observação de um aspecto selecionado da realidade. Esta observação pode ser através dos próprios olhos ou, quando isto não é possível, através de meios audiovisuais, modelos etc. Nesta segunda modalidade de observação, há perdas de informação inerentes a uma representação do real. Ao observar a realidade, os alunos expressam suas percepções pessoais, efetuando-se uma primeira leitura ingênua desta realidade.

Na segunda fase, os alunos separam dessa observação inicial o que é verdadeiramente importante do puramente superficial ou contingente, identificando os pontos-chave do problema ou assunto em questão, as variáveis mais determinantes da situação.

Em um terceiro momento, os alunos passam à teorização do problema ao perguntar ao aluno o porquê das coisas observadas. Recorre-se, então, aos conhecimentos científicos, possibilitando a teorização a partir dos fatos contidos no dia-a-dia, no cotidiano do aluno. Se a teorização é bem-sucedida, o aluno chega a "entender" o problema não somente em suas manifestações empíricas ou situacionais, mas também os princípios teóricos que o explicam. Essa etapa de teorização que compreende operações analíticas da inteligência é altamente enriquecedora e permite o crescimento mental dos alunos. Eis, então, outra razão da superioridade da pedagogia da problematização sobre as de transmissão e condicionamento.

Confrontada a Realidade com sua Teorização, o aluno se vê naturalmente movido a uma quarta fase: a formulação de Hipóteses de Solução para o problema em estudo. O aluno utiliza a realidade para aprender com ela, ao mesmo tempo que se prepara para transformá-la.

Na última fase, o aluno pratica e fixa as soluções encontradas como sendo mais viáveis e aplicáveis. Aprende a generalizar o aprendido para utilizá-lo em situações diferentes e a discriminar em que circunstâncias não é possível ou conveniente a aplicação, explica Bordenave (1999).

Este método pode ser aplicado nas práticas educativas em saúde, como descreve o estudo de Sonobe et al. (2001), que utilizaram o método no ensino pré-operatório de pacientes laringectomizados e obtiveram resultados satisfatórios.

Bordenave (1999) aponta as seguintes repercussões da pedagogia da problematização:

- Em nível individual: (a) aluno constantemente ativo, observando, formulando perguntas, expressando percepções e opiniões; (b)

Figura 1

Passos do processo de ensino-aprendizagem na pedagogia da problematização.

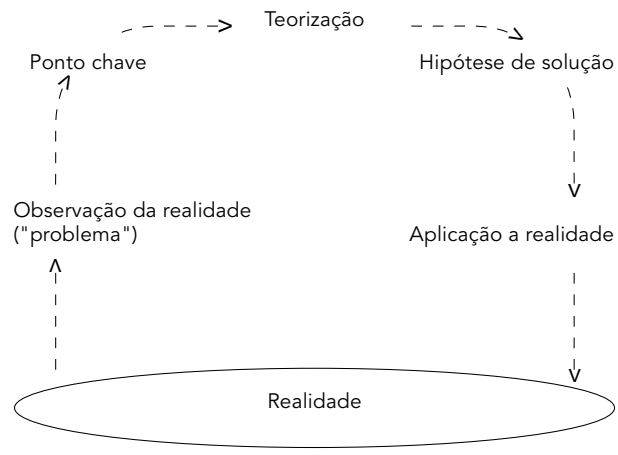


aluno motivado pela percepção de problemas reais cuja a solução se converte em reforço; (c) aprendizagem ligada a aspectos significativos da realidade; (d) desenvolvimento das habilidades intelectuais de observação, análise, avaliação, compreensão, extrapolação etc.; (e) intercâmbio e cooperação com os demais membros do grupo; (f) superação de conflitos como integrante natural da aprendizagem grupal; (g) status do professor não difere do status do aluno.

- Em nível social: (a) população conhecedora de sua própria realidade e reação à valorização excessiva do forâneo (externo); (b) métodos e instituições originais, adequados à própria realidade; redução da necessidade de um líder pois líderes são emergenciais; (c) elevação do nível médio de desenvolvimento intelectual da população, graças a maior estimulação e desafio; (d) criação (ou adaptação) de tecnologia viável e culturalmente compatível; (e) resistência à dominação por classes e países.

Como pedagogia crítica, o modelo educacional de Paulo Freire tem sido apontado como uma importante contribuição para a promoção da saúde, especificamente para a educação em saúde, como pode ser observado nos trabalhos de Kickbusch (2001), McQuiston et al. (2001), Nutbeam (2000) e Wang (2000).

\section{Considerações finais}

As tendências pedagógicas foram expostas aqui de forma sintética. Cada uma delas é produto e expressam uma representação de homem e de sociedade. Embora tenham sido apresentadas em uma seqüência didática e, de certa forma, dentro de um eixo histórico, é importante lembrar que elas ainda coexistem em nossa realidade.

Embora haja críticas a cada uma delas, é indiscutível que a prática educativa norteada pela pedagogia da problematização é mais adequada à pratica educativa em saúde. Além de promover a valorização do saber do educando e instrumentalizando-o para a transformação de sua realidade e de si mesmo, possibilita efetivação do direito da clientela às informações de forma a estabelecer sua participação ativa nas ações de saúde, assim como para o desenvolvimento contínuo de habilidades humanas e técnicas no trabalhador de saúde, fazendo que este exerça um trabalho criativo. Estas características e conseqüências convergem para uma sociedade mais democrática em prol do desenvolvimento das potencialidades dos indivíduos e coletividade estando em concordância com os princípios e diretrizes da Promoção da Saúde.

\section{Referências}

BEHRENS, M. A., 1999. A prática pedagógica e o desafio do paradigma emergente. Revista Brasileira de Estudos Pedagógicos, 80:383-403.

BORDENAVE, J. E. D., 1999. Alguns fatores pedagógicos. In: Capacitação em Desenvolvimento de Recursos Humanos CADRHU (J. P. Santana \& J. L. Castro, org.), pp. 261-268, Natal: Ministério da Saúde/Organização Pan-Americana da Saúde/ Editora da UFRN.

CANDEIAS, N. M. F., 1997. Conceitos de educação e de promoção em Saúde: Mudanças individuais e mudanças organizacionais. Revista de Saúde Pública, 31:209-213.

CNS (Conselho Nacional de Saúde). 2000. $11 \underline{a}$ Conferência Nacional de Saúde: Efetivando o SUS: Acesso, Qualidade e Humanização na atenção à Saúde, com Controle Social - Relatório Final. 15 Julho 2002 <http://conselho.saude.gov.br/11conferencia/ anexos/relatorio.pdf.>. 
COLLARES, C. L.; MOYSÉS, M. A. A. \& GERALDI, J. W., 1999. Educação continuada: A política da descontinuidade. Educação \& Sociedade, 20:202-219.

CORDEIRO, H. \& MINAYO, C., 1997. Saúde: Concepções e políticas públicas. In: Saúde, Trabalho $e$ Formação Profissional (A. A. Amâncio Filho \& M. C. G. Moreira, org.), pp. 49-61, Rio de Janeiro: Editora Fiocruz.

FREIRE, P., 2001. Educação e Mudança. 24a Ed. Rio de Janeiro: Editora Paz e Terra.

KICKBUSCH, I. S., 2001. Health literacy: Addressing the health and education device. Health Promotion International, 16:289-297.

LAVERACK, G., 2001. An identification and interpretation of the organizational aspects of community empowerment. Community Development Journal, 36:134-146.

LIBÂNEO, J. C., 1983. Tendências pedagógicas na prática escolar. Revista da Associação Nacional de Educação-ANDE, 3:11-19.

LUCKESI, C. C., 1994. Filosofia da Educação. São Paulo: Cortez Editora.

McQUISTON, C.; CHOI-HEVEL, S. \& CLAWSON, M., 2001. Protegiendo nuestra comunidad: Empowerment participatory education for HIV prevention. Journal of Transcultural Nursing, 12:275283.
MEC (Ministério da Educação e Cultura), 1997. A tradição pedagógica brasileira. In: Parâmetros Curriculares Nacionais (MEC, org.), pp. 30-33, Brasília: Secretaria de Educação Fundamental, MEC.

NUTBEAM, D., 2000. Health literacy as a public health goal: A challenge for contemporary health education and communication strategies into the $21 \mathrm{st}$ century. Health Promotion International, 15:259267.

OMS (Organização Mundial da Saúde), 1986. Carta de Ottawa. In: Promoção da Saúde e Saúde Pública: Contribuição para o Debate entre as Escolas de Saúde Pública na América Latina (P. M. Buss, org.), pp. 158-162, Rio de Janeiro: Escola Nacional de Saúde Pública, Fundação Oswaldo Cruz.

SAVIANE, D., 1985. Escola e Democracia. 6a Ed. São Paulo: Cortez Editora.

SONOBE, H. M.; HAYASHIDA, M.; MENDES, A. C. \& ZAGO, M. M. F., 2001. O método do arco no ensino pré-operatório de pacientes laringectomizados. Revista Brasileira de Cancerologia, 47:425433.

WANG, R., 2000. Critical health literacy: A case study from China in schistosomiasis control. Health Promotion International, 15:269-274.

Recebido em 3 de setembro de 2002

Versão final reapresentada em 17 de dezembro de 2002 Aprovado em 16 de abril de 2003 